\title{
Molecular diagnosis and phylogenetic analysis of Babesia bigemina and Babesia bovis hemoparasites from cattle in South Africa
}

\author{
Moses Sibusiso Mtshali ${ }^{1,2^{*}}$ and Phillip Senzo Mtshali ${ }^{1}$
}

\begin{abstract}
Background: Babesia parasites, mainly Babesia bovis and B. bigemina, are tick-borne hemoparasites inducing bovine babesiosis in cattle globally. The clinical signs of the disease include, among others, anemia, fever and hemoglobinuria. Babesiosis is known to occur in tropical and subtropical regions of the world. In this study, we aim to provide information about the occurrence and phylogenetic relationship of B. bigemina and B. bovis species in cattle from different locations in nine provinces of South Africa.

A total of 430 blood samples were randomly collected from apparently healthy cattle. These samples were genetically tested for Babesia parasitic infections using nested PCR assays with species-specific primers.

Results: Nested PCR assays with Group I primer sets revealed that the overall prevalence of B. bigemina and B. bovis in all bovine samples tested was $64.7 \%(95 \% \mathrm{Cl}=60.0-69.0)$ and $35.1 \%(95 \% \mathrm{Cl}=30.6-39.8)$, respectively. Only $117 /$ $430(27.2 \%)$ animals had a mixed infection. The highest prevalence of $87.5 \%(95 \% \mathrm{Cl}=77.2-93.5)$ for B. bigemina was recorded in the Free State province collection sites (Ficksburg, Philippolis and Botshabelo), while North West collection sites had the highest number of animals infected with B. bovis (65.5\%; 95\% Cl=52.7-76.4). Phylograms were inferred based on B. bigemina-specific gp45 and B. bovis-specific rap-1 nucleotide sequences obtained with Group II nested PCR primers. Phylogenetic analysis of gp45 sequences revealed significant differences in the genotypes of B. bigemina isolates investigated, including those of strains published in GenBank. On the other hand, a phylogeny based on $B$. bovis rap-1 sequences indicated a similar trend of clustering among the sequences of B. bovis isolates investigated in this study.

Conclusion: This study demonstrates the occurrence of Babesia parasites in cattle from different provinces of South Africa. It was also noted that the situation of Babesia parasitic infection in cattle from certain areas within the surveyed provinces had either reached endemic stability or was progressing towards stability.
\end{abstract}

Keywords: Cattle, Babesia bigemina, Babesia bovis, South Africa, Nested PCR, Phylogeny

\section{Background}

Bovine babesiosis (also known as redwater) is one of the most economically important infectious diseases affecting cattle worldwide. This tick-borne disease is mainly induced by intraerythrocytic protozoan parasites of the genus Babesia, order Piroplasmida and phylum Apicomplexa [1]. In southern Africa, Babesia bigemina and

\footnotetext{
*Correspondence: sibusiso@nzg.ac.za

${ }^{1}$ Research and Scientific Services Department, Veterinary Parasitology Unit, National Zoological Gardens of South Africa, Pretoria 0001, South Africa ${ }^{2}$ Department of Zoology and Entomology, Parasitology Research Program, University of the Free State, Qwaqwa Campus, Phuthaditjhaba 9866, South Africa
}

\section{Biomed Central

(c) 2013 Mtshali and Mtshali; licensee BioMed Central Ltd. This is an Open Access article distributed under the terms of the Creative Commons Attribution License (http://creativecommons.org/licenses/by/2.0), which permits unrestricted use, distribution, and reproduction in any medium, provided the original work is properly cited.
Babesia bovis are the two economically important species infecting cattle and have high prevalence in tropical and subtropical regions of the world [2]. Clinical signs characterizing the disease caused by the two parasites are anemia, fever, hemoglobinuria, and in many cases death $[3,4]$.

Traditionally, the microscopic detection of Babesia parasites has always been considered as the gold standard for the diagnosis of acute babesiosis [5]. However, the major drawback associated with microscopic examination of blood parasites is the low sensitivity offered by the technique, thus making it difficult to detect parasites in blood smears during low parasitemia in the case 
of carrier animals [6]. Alternatively, PCR-based assays have been widely used for the detection of Babesia parasites owing to their high specificity and sensitivity [4,6-9].

At present, there are still limited tools available for the prevention and eradication of bovine babesiosis. By far, the most recommended approach for controlling ticks and tick-borne diseases in South Africa is by integrating the strategic use of acaricides (i.e. the pesticides used for killing ticks) and application of vaccines [10]. However, more than $90 \%$ of resource-poor farmers contend that the dip wash is not effective in killing the ticks. Consequently, these farmers complement the government dipping service with their own initiatives, which include spraying with conventional acaricides, using household disinfectants and manual removal $[11,12]$.

It is estimated that, in South Africa, approximately $18 \%$ of all cattle mortalities are due to tick-borne diseases including babesiosis, anaplasmosis and heartwater [10]. These diseases have a considerable impact on the country's economic security and also impact negatively on poor communities who are dependent on livestock production as their source of income and nutritional needs (meat and milk), and as labour for fieldwork and transport [13]. As such, it is reported that the occurrence of B. bigemina and B. bovis in South African cattle population hampers the development of livestock industry, which accounts for up to $49 \%$ of the agricultural output [14].

Given the importance of livestock production in the South African economic landscape, in this study, we genetically investigated the occurrence and distribution of Babesia parasites, more specifically B. bigemina and $B$. bovis, in bovine samples randomly collected from different locations throughout South Africa. We also studied the phylogenetic relatedness amongst DNA sequences of randomly selected bovine samples.

\section{Methods}

\section{Blood sample collection}

Experimental collection of blood samples from cattle was approved by the NZG Ethics and Scientific Committee, National Zoological Gardens of South Africa. Between 2010 and 2012, a total of 430 blood samples were randomly collected from clinically healthy cattle occupying different locations in all nine provinces of South Africa: Mpumalanga province (Ehlanzeni South District; $n=48$ ), KwaZulu-Natal province (Albert Falls, Ndaleni dip tank and Shallow Drift; $n=52$ ), Limpopo province (Capricorn District; $n=47$ ), North West province (Maubane and Mmatlhwaela; $n=58$ ), Gauteng province (Bronkhorstspruit; $n=30$ ), Free State province (Ficksburg, Philippolis and Botshabelo; $n=64$ ), Eastern Cape province (Alice, Fort Beaufort and Adelaide; $n=60$ ), Northern Cape province (Kuruman; $n=45$ ) and Western Cape province
(Boland area; $n=26$ ). The total number of animals sampled in each collection site depended on the number of cattle present at the sampling stations (dip tanks/cattle farms). No information on the age groups, husbandry practices, vaccination histories and tick infestation status of the sampled cattle were available, given that other bovine blood samples were collected and provided by the farmers. Blood was collected from the coccygeal vein into EDTA-coated vacutainer tubes, transported to the laboratory on ice and stored at $-20^{\circ} \mathrm{C}$ until further analysis.

\section{DNA extraction}

Genomic DNA was extracted from $200 \mu$ of blood using ZR Genomic DNA ${ }^{\mathrm{Tm}}$-Tissue MiniPrep kit (Inqaba Biotechnical Industries, Pretoria, South Africa) according to the manufacturer's instructions. Extracted DNA was eluted in $50 \mu \mathrm{l}$ of DNA elution buffer and stored at $-20^{\circ} \mathrm{C}$ until further analysis. DNA concentration was determined using a NanoDrop ${ }^{\circ}$ ND-1000 (NanoDrop Technologies Inc., Wilmington, USA).

\section{Primer design}

Four sets of oligonucleotide primers reported previously [8] were employed for detecting B. bigemina and B. bovis parasites in field blood samples. To obtain DNA sequences for phylogenetic analysis, new sets of speciesspecific primers were designed (Table 1). These primers targeted merozoite surface glycoprotein 45 (gp 45) and rhoptry-associated protein 1 (rap-1) genes specific for $B$. bigemina and B. bovis, respectively. The gp 45 gene sequences of $B$. bigemina used for primer design were extracted from GenBank under accession numbers JN049649-JN049655 and AF298631-AF298632. The GenBank accession numbers for B. bovis rap-1 sequences were FJ588009-FJ588013 and AF030056-AF030060.

The new pairs of PCR and nested PCR primers were designed from conserved regions identified after performing multiple sequence alignments with CLUSTAL W algorithm [15] embedded in BioEdit software [16]. The specificity of newly designed primers was tested against GenBank sequences using BLAST search [17]. All primers were synthesized by Inqaba Biotechnical Industries.

\section{Specificity of nested PCR}

Purified DNA samples of B. bigemina, B. bovis, Anaplasma centrale, Theileria parva and Ehrlichia ruminantium were used to assess the specificity of Group I and Group II primers. These DNA samples were kindly provided by Dr Nicola Collins (Department of Veterinary Tropical Diseases, University of Pretoria, South Africa) and Dr Oriel Thekisoe (Parasitology Research Program, University of the Free State, South Africa). PCR and nested PCR mixtures were prepared 
Table 1 Primary and nested PCR primers used for PCR amplifications

\begin{tabular}{|c|c|c|c|c|}
\hline Species & Assay & Primer sequence $\left(5^{\prime} \rightarrow 3^{\prime}\right)$ & Annealing & Product size \\
\hline \multicolumn{5}{|c|}{ Oligonucleotides used for screening (Group I) $^{\mathrm{a}}$} \\
\hline \multirow[t]{4}{*}{ B. bigemina } & PCR & F-САTCTAATTTCTCTCCATACCССТCC & $55^{\circ} \mathrm{C}$ & $278 \mathrm{bp}$ \\
\hline & & R-CCTCGGCTTCAACTCTGATGCCAAAG & & \\
\hline & $\mathrm{nPCR}$ & F-CGCAAGCCCAGCACGCCCCGGTGC & $55^{\circ} \mathrm{C}$ & $170 \mathrm{bp}$ \\
\hline & & R-CCGACCTGGATAGGCTGTGTGATG & & \\
\hline \multirow[t]{4}{*}{ B. bovis } & PCR & F-CACGAGGAAGGAACTACCGATGTTGA & $55^{\circ} \mathrm{C}$ & $360 \mathrm{bp}$ \\
\hline & & R-CCAAGGAGCTTCAACGTACGAGGTCA & & \\
\hline & $\mathrm{nPCR}$ & F-TCAACAAGGTACTCTATATGGCTACC & $55^{\circ} \mathrm{C}$ & $298 \mathrm{bp}$ \\
\hline & & R-CTACCGAGCAGAACCTTCTTCACCAT & & \\
\hline \multicolumn{5}{|c|}{ Oligonucleotides used for phylogenetic study (Group II) } \\
\hline \multirow[t]{4}{*}{ B. bigemina } & PCR & F-GTGCTGCTTAATCGCACAAAC & $55^{\circ} \mathrm{C}$ & $963 \mathrm{bp}$ \\
\hline & & R-AAGATGCCTTCTTCGGTGATG & & \\
\hline & $\mathrm{nPCR}$ & F-CGGATCCTGTTATCGTTCCTG & $56^{\circ} \mathrm{C}$ & $853 \mathrm{bp}$ \\
\hline & & R-GAAGTTACGCCTGGAGTTGG & & \\
\hline \multirow[t]{4}{*}{ B. bovis } & PCR & F-TCAGATTGTTCAAAGAGAGTGCATCC & $55^{\circ} \mathrm{C}$ & $1280 \mathrm{bp}$ \\
\hline & & R-GTCTTCACCGTTGGAAGTAGTTGAGTC & & \\
\hline & $\mathrm{nPCR}$ & F-CACGAGGAAGGAACTACCGATGTTGA & $64^{\circ} \mathrm{C}$ & $1009 \mathrm{bp}$ \\
\hline & & R-CCTITGTAGGTTGGCCAACAGTTTCG & & \\
\hline
\end{tabular}

${ }^{a}$ Group I oligonucleotide sequences were taken from published work [8]

${ }^{b}$ Group II primers were designed in this study.

and thermally cycled as described above using $2 \mu \mathrm{l}$ of each of the purified DNA samples.

\section{PCR detection assays}

To detect the presence of $B$. bigemina and B. bovis from bovine samples using Group I primers, PCR was performed in a $25-\mu \mathrm{l}$ reaction mixture containing $5 \mu \mathrm{l}$ of the extracted DNA, $0.6 \mu \mathrm{M}$ of each primer and $12.5 \mu \mathrm{l}$ of DreamTaq Green PCR Master Mix (Inqaba Biotechnical Industries). Negative control reactions contained distilled water instead of template DNA. Reaction mixtures were subjected to PCR using BIO-RAD T100 ${ }^{\text {ma }}$ Thermal Cycler (Bio-Rad Laboratories, Johannesburg, South Africa). PCR amplifications (round 1) were performed at the following thermal conditions: $95^{\circ} \mathrm{C}$ for $3 \mathrm{~min}$, followed by 35 cycles of $95^{\circ} \mathrm{C}$ for $30 \mathrm{sec}, 55^{\circ} \mathrm{C}$ for $45 \mathrm{sec}$ and $72^{\circ} \mathrm{C}$ for $1 \mathrm{~min}$. Following the final extension step at $72^{\circ} \mathrm{C}$ for $10 \mathrm{~min}, 1 \mu \mathrm{l}$ of each PCR product was added into the second (nested) PCR mixture comprising similar composition of reagents as the first round PCR, except that the external primers were replaced with the nested PCR primers. PCR mixtures were cycled as described above using annealing temperatures reflected in Table 1.

PCR-generated amplicons were analyzed by electrophoresis in 1.5\% agarose gels stained with Biotium GelRed Acid Stain (Anatech Instruments, Johannesburg, South Africa) and visualized under UV illumination. GeneRuler ${ }^{\mathrm{ma}} 1 \mathrm{~kb}$
Plus DNA ladder (Inqaba Biotechnical Industries) was used as the standard molecular weight marker.

\section{Sequencing and phylogenetic analysis}

For phylogenetic study, genomic DNA of randomly selected field samples was amplified with Group II nested PCR primers (Table 1) targeting gp 45 and rap-1 fragments of $B$. bigemina and B. bovis, respectively. Seven bovine samples were selected for B. bigemina and six for B. bovis. PCR mixtures were prepared and thermally cycled as described above employing the annealing temperatures reflected in Table 1. PCR-generated fragments of $853 \mathrm{bp}$ (for B. bigemina) and 1009 bp (for B. bovis) were sent to Inqaba Biotechnical Industries for purification and sequencing in both directions using ABI 3130 XL Genetic Analyzer (Applied Biosystems, Johannesburg, South Africa). At least two individually amplified DNA fragments of each selected sample were sequenced.

Nucleotide sequences were assembled and aligned using BioEdit software program [16]. The resulting consensus sequences were subsequently used to search for homologous sequences in GenBank. To construct phylogenetic trees, the consensus nucleotide sequences were trimmed manually to equivalent lengths. Phylogenies were inferred using the neighbour-joining algorithm of the MEGA v4.1 software [18]. Bootstrapping analysis with 1000 replicates was used to estimate the robustness of individual branches [19]. 


\section{Nucleotide sequence accession numbers}

The determined B. bigemina gp 45 and B. bovis rap-1 gene sequences were submitted to GenBank database under the accession numbers KC894392-KC894404.

\section{Statistical analysis}

The proportions for 95\% confidence intervals (95\% CI) were computed as CIs for proportions with binomial data employing no continuity correction.

\section{Results and discussion}

Blood samples collected from 430 cattle were genetically tested for the presence of Babesia parasites. Nested PCR assays with Group I primers developed previously [8] were employed to detect $B$. bigemina and B. bovis pathogens in bovine samples collected from different locations throughout South Africa. The samples presenting single amplification fragments of approximately $170 \mathrm{bp}$ and 298 bp were considered positive for B. bigemina and $B$. bovis, respectively. The results of nested PCR amplification assays are presented in Table 2.

The animals infected with $B$. bigemina and $B$. bovis were found in all the provinces surveyed, albeit there were differences observed in the distribution of these hemoparasites in cattle from certain provinces. The occurrence of B. bigemina and B. bovis in cattle from all surveyed areas could be attributed to the presence and distribution of tick vectors transmitting these parasites. Nested PCR assays detected mostly $B$. bigemina compared to $B$. bovis, and these results are similar to previous findings reported elsewhere [20-22]. However, a notable exception was evident for blood samples collected from Kuruman in the Northern Cape province where the occurrence of both Babesia species was below $5 \%$. This low prevalence is not unusual for an area that is considered free of babesiosis tick vectors.

The overall prevalence of B. bigemina and B. bovis in all samples was $64.7 \%(95 \% \mathrm{CI}=60.0-69.0)$ and $35.1 \%$
(95\% CI = 30.6-39.8), respectively. Samples from the Free State province had the highest frequency of $B$. bigemina (87.5\%, 95\% CI =77.2-93.5), followed by KwaZulu-Natal province with as high as $84.6 \%(95 \% \mathrm{CI}=72.5-92.0)$ of samples tested positive for $B$. bigemina. These high prevalence values (>80\%) were indicative of an endemically stable situation [23]. By definition, an endemically stable situation occurs when $81-100 \%$ of the herd are infected with a particular Babesia species [23]. The highest number of samples positive for $B$. bovis was recorded in the North West province collection sites $(65.5 \%, 95 \% \mathrm{CI}=52.7-76.4)$, thus indicating the situation approaching endemic stability but with the potential occurrence of disease outbreaks [23]. Of all the collection sites surveyed, Kuruman area in Northern Cape province had the lowest prevalence of $4.4 \%$ ( 2 out of $45 ; 95 \% \mathrm{CI}=$ 1.2-14.8) for both B. bigemina and B. bovis. The cattle found to contain DNA of both $B$. bigemina and $B$. bovis $(117 / 430,27.2 \%)$ originated from all but one of the nine provinces from which blood samples were collected. None of the blood samples collected from Kuruman (Northern Cape province) possessed mixed infections.

In principle, the occurrence of $B$. bigemina and $B$. bovis in cattle is largely dependent on the distribution of tick vectors [24]. The sole vector of B. bovis in South Africa is Rhiphicephalus (Boophilus) microplus, whereas B. bigemina is transmitted by $R$. (B.) microplus, Rhiphicephalus (Boophilus) decoloratus and Rhiphice phalus evertsi evertsi [3]. Based on the geographical distribution of tick species in South Africa, $R$. (B.) microplus is more prevalent in KwaZulu-Natal, Eastern Cape and Limpopo provinces, while the high prevalence of $R$. (B.) decoloratus was recorded in Mpumalanga, Eastern Cape and KwaZulu-Natal provinces. On the other hand, $R$. evertsi evertsi is reported to be present throughout South Africa, except in arid areas of the Northern Cape and northern Western Cape provinces [25-29].

Table 2 Nested PCR detection results of B. bigemina and B. bovis parasites in field blood samples

\begin{tabular}{|c|c|c|c|c|c|c|c|}
\hline \multirow[t]{2}{*}{ Province } & \multirow{2}{*}{$\begin{array}{l}\text { Total number } \\
\text { of samples }\end{array}$} & \multicolumn{2}{|c|}{ Babesia bigemina } & \multicolumn{2}{|c|}{ Babesia bovis } & \multicolumn{2}{|c|}{ Mixed infection } \\
\hline & & No. positive & Percentage & No. positive & Percentage & No. positive & Percentage \\
\hline Mpumalanga & 48 & 32 & 66.7 & 21 & 43.8 & 15 & 31.3 \\
\hline KwaZulu-Natal & 52 & 44 & 84.6 & 33 & 63.5 & 28 & 53.9 \\
\hline Limpopo & 47 & 39 & 83.0 & 11 & 23.4 & 11 & 23.4 \\
\hline North West & 58 & 41 & 70.7 & 38 & 65.5 & 24 & 41.4 \\
\hline Gauteng & 30 & 25 & 83.3 & 19 & 63.3 & 18 & 60.0 \\
\hline Free State & 64 & 56 & 87.5 & 15 & 23.4 & 14 & 21.9 \\
\hline Eastern Cape & 60 & 21 & 35.0 & 7 & 11.7 & 4 & 6.7 \\
\hline Northern Cape & 45 & 2 & 4.4 & 2 & 4.4 & 0 & 0 \\
\hline Western Cape & 26 & 18 & 69.2 & 5 & 19.2 & 3 & 11.5 \\
\hline Total & 430 & 278 & 64.7 & 151 & 35.1 & 117 & 27.2 \\
\hline
\end{tabular}


Therefore, it is not surprising that in the present study, there was a high percentage of bovine samples positive for $B$. bigemina and $B$. bovis infections. These results confirm the previous findings that Babesia infections are common in cattle in South Africa [14,30,31]. Using serology-based assays, a recent study [14] demonstrated the existence of B. bigemina and B. bovis parasites in cattle from eight South African provinces surveyed. Surprisingly, more than $20 \%$ of animals from Northern Cape province were found to possess B. bigemina and $B$. bovis when tested with IFAT and ELISA [14], and these values are considered higher for an area known to be free of $R$. (B.) microplus, $R$. (B.) decoloratus and $R$. evertsi evertsi tick vectors. According to the latter authors [14], the higher prevalence values could be explained by the possible outsourcing of animals from endemic areas in the neighbouring provinces.

To study the phylogenetic relationship between Babesia parasites of randomly selected bovine samples, new sets of nested PCR primers (Group II) were designed based on nucleotide sequences of the gp 45 (B. bigeminaspecific) and rap-1 (B. bovis-specific) genes. The specificity of both Group I and Group II primers was tested against purified DNA samples of B. bigemina, B. bovis, $A$. centrale, T. parva and E. ruminantium. As expected, the nested PCR assay with $B$. bigemina gene-specific primers only detected the DNA of $B$. bigemina. Likewise, B. bovis-specific nested PCR assay specifically identified $B$. bovis DNA sample, and no amplifications were observed for DNA samples derived from B. bigemina, $A$. marginale, T. parva and E. ruminantium.

The neighbour-joining tree inferred with gp 45 gene sequences of B. bigemina isolates determined in this study is shown in Figure 1. The closely related sequences of B. bigemina gp 45 genes retrieved from GenBank were also incorporated in the phylogeny. From the phylogenetic analysis, it was worth noting that our isolates were clearly distinct from other closely related taxa whose sequences were obtained from GenBank database (Figure 1). Interestingly, WC-11130 isolate (accession no. KC894398) clustered with B. bigemina strains from GenBank, suggesting the high genetic similarity of our isolate with published strains. As highlighted in the literature, the diversity observed between gp 45 sequences of B. bigemina is not unusual. The high polymorphism of gp 45 B-cell epitopes amongst the American isolates of $B$. bigemina was reported previously [32]. Given the nucleic acid sequence variations observed amongst the tested $B$. bigemina isolates, it may be expected that these sequence heterogeneities would induce changes in the protein structure.

In a phylogram generated with rap-1 gene sequences of B. bovis, as presented in Figure 2, it appears that

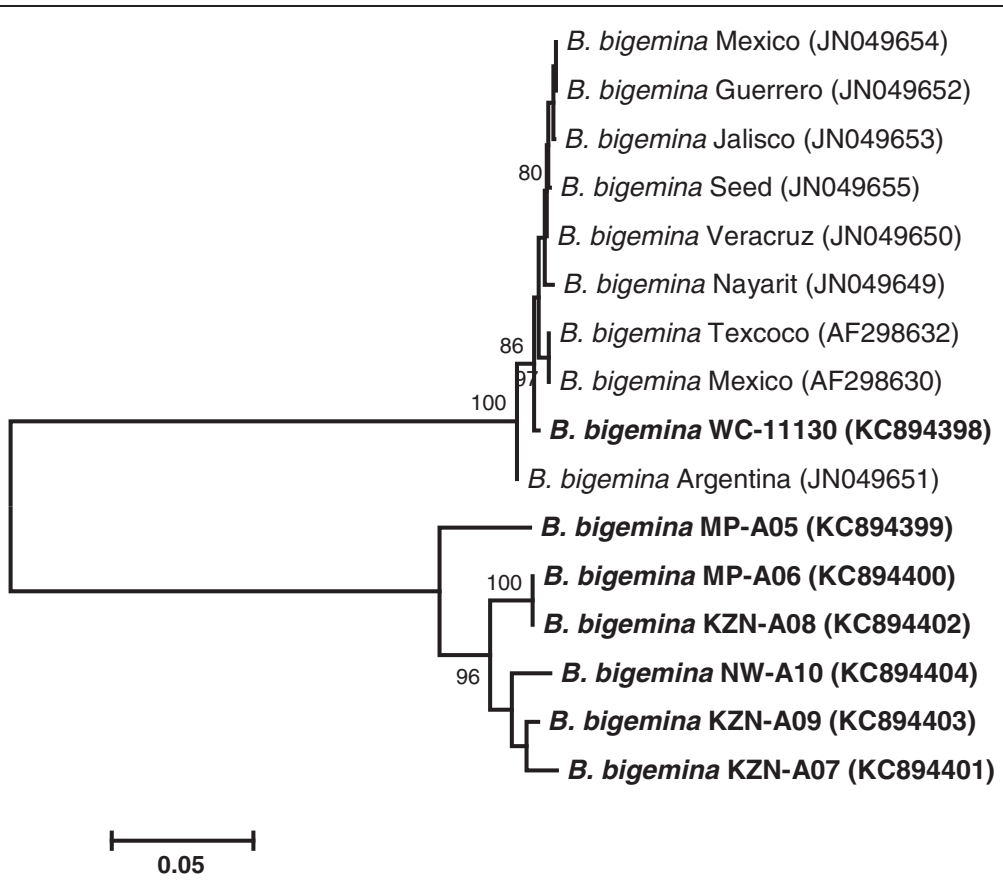

Figure 1 Phylogenetic tree inferred from partial gp45 nucleotide gene sequences (818-827 $n t$ ) and showing the relationship between B. bigemina isolates investigated in this study (indicated in bold) and other B. bigemina strains published in GenBank (accession numbers in parentheses). The tree was constructed using the neighbour-joining algorithm of MEGA v4.1 software. The numbers at the nodes are bootstrap values expressed as percentages of 1000 replicates; only the values above $80 \%$ are shown. The bar (0.05) represents the number of mutations per site. Isolate designations: MP - Mpumalanga province, NW - North West province, WC - Western Cape province, and KZN KwaZulu-Natal province. 


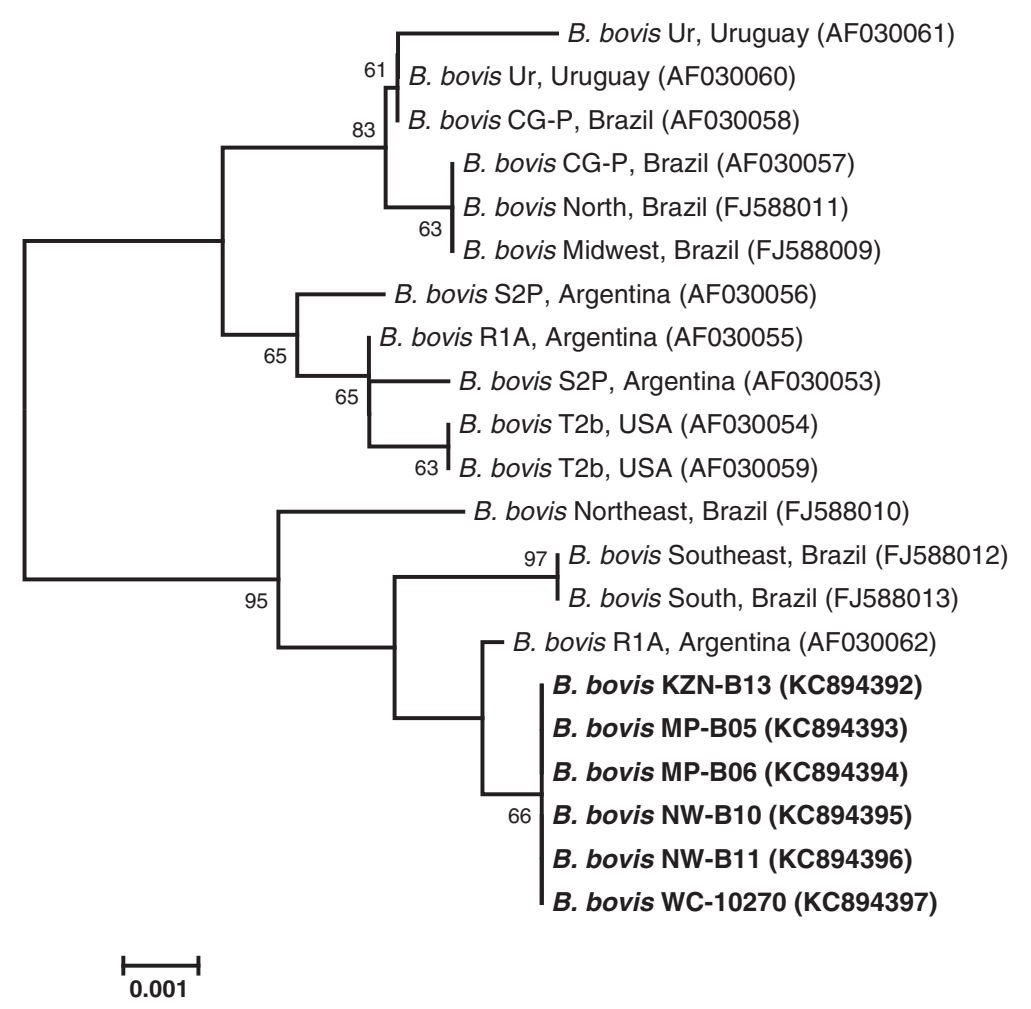

Figure 2 Phylogenetic tree based on rap-1 gene sequences ( $947 \mathrm{nt}$ ) of $B$. bovis isolates identified in this study (indicated in bold) and those of strains whose sequences were extracted from GenBank (accession numbers in parentheses). The tree was constructed using the neighbour-joining method, with bootstrap values (expressed as percentages of 1000 replications) superimposed at branching points; only the values above $60 \%$ are shown. The horizontal bar represents the number of base substitutions per site. Isolate designations: MP - Mpumalanga province, NW - North West province, WC - Western Cape province, and KZN - KwaZulu-Natal province.

B. bovis isolates tested in this study are phylogenetically similar to B. bovis strains originating from countries other than South Africa. Results on the genetic conservation between rap-1 sequences of $B$. bovis strains have also been reported elsewhere [33,34]. Nevertheless, our isolates formed a monophyletic grouping clearly distinct from that of other published $B$. bovis strains, and this suggested the presence of micro-heterogeneities among the rap-1 sequences within B. bovis species.

\section{Conclusion}

The results presented in this study demonstrate a high incidence of cattle infection by B. bigemina and $B$. bovis in sampling areas from all provinces surveyed, with a notable exception of Kuruman area (Northern Cape province) that displayed a very low occurrence of Babesia parasites. The high prevalences $(>80 \%)$ of B. bigemina in cattle from KwaZulu-Natal, Limpopo, Gauteng and Free State sampling areas suggest that the situation of $B$. bigemina infection has reached endemic stability. Conversely, the prevalence of $B$. bovis in bovine samples from KwaZulu-Natal,
North West and Gauteng collection sites suggests that the situation in these areas is progressing towards endemic stability. Therefore, in order to attain endemic stability to Babesia parasites, a limited number of tick vectors should be allowed to infest cattle, particularly in the case of herds occupying areas with lower infection rates.

In addition, this study has expanded our current knowledge concerning the genetic diversity and phylogenetic relatedness among B. bigemina and B. bovis isolates of South African origin. Given the limited number of Babesia-specific gene sequences available in GenBank, particularly those of Babesia species originating from South African cattle, further studies incorporating sampling sites representative of each surveyed province would be required. Undoubtedly, this will enable a better understanding of the epidemiology of bovine babesiosis as well as the degree of genetic heterogeneities among $B$. bigemina and $B$. bovis isolates in South African cattle. Overall, the findings from this study will ultimately help farmers develop efficient control strategies to curtail cattle mortalities emanating from bovine babesiosis. 


\section{Competing interests}

The authors declare that they have no competing interests.

\section{Authors' contributions}

MS conceived and designed the study. PS performed laboratory experiments, participated in data analysis, constructed and interpreted phylogenetic trees, and drafted the manuscript. MS and PS critically reviewed the first draft of the manuscript. All authors read and approved the final version of the manuscript.

\section{Acknowledgements}

The authors are indebted to Dr Nicola Collins and Dr Oriel Thekisoe who kindly provided the purified DNA samples of B. bigemina, B. bovis, A. centrale, T. parva and E. ruminantium. The authors are also grateful to A. Tsotetsi, S. Ntanta, M. Legodi, A.M. Mutshembele, L. Seseni and I.D.B. Sekwati for their technical assistance. The farmers who participated in bovine sample collection are gratefully acknowledged. This work is based on the research supported by the National Research Foundation (NRF) and the National Zoological Gardens of South Africa (NZG). Any opinion, finding and conclusion or recommendation expressed in this material is that of the authors and the NRF does not accept any liability in this regard.

Received: 15 April 2013 Accepted: 2 August 2013

Published: 8 August 2013

\section{References}

1. McCosker PJ: The global importance of babesiosis. In Babesiosis. Edited by Ristic M, Kreier JP. New York: Academic; 1981:1-24.

2. Bock R, Jackson L, de Vos A, Jorgensen W: Babesiosis of cattle. Parasitol 2004, 129:247-269.

3. de Vos AJ, Potgieter FT: Bovine babesiosis. In Infectious diseases of livestock. Edited by Coetzer JAW, Thomson GR, Tustin RC. Cape Town: Oxford University Press; 1994:278-294. 1994.

4. Martins TM, Pedro OC, Caldeira RA, do Rosário VE, Neves L, Domingos A: Detection of bovine babesiosis in Mozambique by a novel seminested hot-start PCR method. Vet Parasitol 2008, 153:225-230.

5. Böse R, Jorgensen WK, Dalgliesh RJ, Friedhoff KT, de Vos AJ: Current state and future trends in the diagnosis of babesiosis. Vet Parasitol 1995, 57:61-74.

6. Almeria S, Castella J, Ferrer D, Ortuno A, Estrada-Peña A, Gutierrez JF: Bovine piroplasms in Minorca (Balearic Islands, Spain): a comparison of PCR-based and light microscopy detection. Vet Parasitol 2001, 99:249-259.

7. Fahrimal Y, Goff WL, Jasmer DP: Detection of Babesia bovis carrier cattle by using polymerase chain reaction amplification of parasite DNA. J Clin Microbiol 1992, 30:1374-1379.

8. Figueroa JV, Chieves LP, Johnson GS, Buening GM: Multiplex polymerase chain reaction based assay for the detection of Babesia bigemina, Babesia bovis and Anaplasma marginale DNA in bovine blood. Vet Parasitol 1993, 50:69-81.

9. AbouLaila M, Yokoyama N, Igarashi I: Development and evaluation of two nested PCR assays for the detection of Babesia bovis from cattle blood. Vet Parasitol 2010, 172:65-70.

10. De Waal DT: Anaplasmosis control and diagnosis in South Africa. Ann N Y Acad Sci 2000, 916:474-483.

11. Masika PJ, Sonandi A, van Averbeke W: Tick control by small-scale cattle farmers in the central Eastern Cape Province, South Africa. J S Afr Vet Assoc 1997, 68:45-48.

12. Moyo B, Masika PJ: Tick control methods used by resource-limited farmers and the effect of ticks on cattle in rural areas of the Eastern Cape Province, South Africa. Trop Anim Health Prod 2009, 41:517-523.

13. Perry BD, Sones KR: Poverty reduction through animal health. Science 2007, 315:333-334.

14. Terkawi MA, Thekisoe OMM, Katsande C, Latif AA, Mans BJ, Matthee O, Mkize N, Mabogoane N, Marais F, Yokoyama N, Xuan X, Igarashi I: Serological survey of Babesia bovis and Babesia bigemina in cattle in South Africa. Vet Parasitol 2011, 182:337-342.

15. Thompson JD, Higgins DG, Gibson TJ: CLUSTAL W: improving the sensitivity of progressive multiple sequence alignment through sequence weighting, position-specific gap penalties and weight matrix choice. Nucleic Acids Res 1994, 22:4673-4680.
16. Hall TA: BioEdit: a user-friendly biological sequence alignment editor and analysis program for Windows 95/98/NT. Nucleic Acids Symp Ser 1999, 41:95-98.

17. Altschul SF, Gish W, Miller W, Myers EW, Lipman DJ: Basic local alignment search tool. J Mol Biol 1990, 215:403-410.

18. Kumar S, Nei M, Dudley J, Tamura K: MEGA: a biologist-centric software for evolutionary analysis of DNA and protein sequences. Brief Bioinform 2008, 9:299-306.

19. Felsenstein J: Confidence limits on phylogenies: an approach using the bootstrap. Evolu 1985, 39:783-791.

20. Applewhaite LM, Craig TM, Wagner GG: Serological prevalence of bovine babesiosis in Guyana. Trop Anim Health Prod 1981, 13:13-18.

21. Miller DK, Diall O, Craig TM, Wagner GG: Serological prevalence of bovine babesiosis in Mali. Trop Anim Health Prod 1984, 16:71-77.

22. Jongejan F, Perry BD, Moorhouse PD, Musisi FL, Pegram RG, Snacken M: Epidemiology of bovine babesiosis and anaplasmosis in Zambia. Trop Anim Health Prod 1988, 20:234-242.

23. Norval RAI, Fivaz BH, Lawrence JA, Dailecourt T: Epidemilogy of tick-borne diseases of cattle in Zimbabwe: I. Babesiosis. Trop Anim Health Prod 1983, 15:87-94.

24. de Vos AJ: Epidemiology of bovine babesiosis in South Africa. Onderstepoort J Vet Res 1979, 50:357-362.

25. Baker MK, Ducasse FBW, Sutherst RW, Maywald GF: The seasonal tick populations on traditional and commercial cattle grazed at four altitudes in Natal. J S Afr Vet Assoc 1989, 60:95-101.

26. Fourie $\sqcup$, Kok DJ, Heyne H: Adult ixodid ticks on two cattle breeds in the south-western Free State, and their seasonal dynamics. Onderstepoort J Vet Res 1996, 63:19-23.

27. Bryson NR, Tice GA, Horak IG, Stewart CG, Du Plessis BJA: Ixodid ticks on cattle belonging to small-scale farmers at 4 communal grazing areas in South Africa. J S Afr Vet Assoc 2002, 73:98-103.

28. Tønnesen MH, Penzhorn BL, Bryson NR, Stoltsz WH, Masibigiri T: Displacement of Boophilus decoloratus by Boophilus microplus in the Soutpansberg region, Limpopo Province, South Africa. Exp Appl Acarol 2004, 32:199-208.

29. Marufu MC, Chimonyo M, Mapiye C, Dzama K: Tick loads in cattle raised on sweet and sour rangelands in the low-input farming areas of South Africa. Trop Anim Health Prod 2011, 43:307-313.

30. Dreyer K, Fourie LJ, Kok DJ: Epidemiology of tick-borne diseases of cattle in Botshabelo and Thaba Nchu in the Free State Province. Onderstepoort J Vet Res 1998, 65:285-289.

31. Tønnesen MH, Penzhorn BL, Bryson NR, Stoltsz WH, Masibigiri T: Seroprevalence of Babesia bovis and Babesia bigemina in cattle in the Soutpansberg region, Limpopo Province, South Africa, associated with changes in vector-tick populations. J S Afr Vet Assoc 2006, 77:61-65.

32. Fisher TG, McElwain TF, Palmer GH: Molecular basis for variable expression of merozoite surface antigen gp45 among American isolates of Babesia bigemina. Infect Immun 2001, 69:3782-3790.

33. Silva MG, Henriques G, Sánchez C, Marques PX, Suarez CE, Oova A: First survey for Babesia bovis and Babesia bigemina infection in cattle from Central and Southern regions of Portugal using serological and DNA detection methods. Vet Parasitol 2009, 166:66-72.

34. Ramos CA, Araújo FR, Alves LC, de Souza II, Guedes DS Jr, Soares CO: Genetic conservation of potentially immunogenic proteins among Brazilian isolates of Babesia bovis. Vet Parasitol 2012, 187:548-552.

\section{doi:10.1186/1746-6148-9-154}

Cite this article as: Mtshali and Mtshali: Molecular diagnosis and phylogenetic analysis of Babesia bigemina and Babesia bovis hemoparasites from cattle in South Africa. BMC Veterinary Research 2013 9:154. 